\title{
Zooming survey on the actual situation of the sustainable development in China from 1970 until now.
}

\author{
Azaiez Mohamed Saiefeddine*, Afef Bouzoraa, Liu Xiaohu \\ School of Architecture \& Urban Planning, Huazhong University of Science and Technology, Wuhan, China
}

\begin{abstract}
Sustainable development in China could have a vital impact both nationally and globally, and its intensive external and internal factors call for a strong commitment to sustainable development. The policies changes have strengthened the urgency and importance of assuming sustainable responsibility in all realms and processes, including architectural practices and village development. However, with regard to the problems identified above not well controlled ecological deterioration and other barriers, sustainable development in China has a long way to go. This kindly indicates that the broad and general aims of policies without detailed explanation of practical application or action at down level are insufficient to make significant changes in practice. As a result, more specific and effective measures and actions are needed to address the complex and challenging issues and make difference. The construction field in China represents the biggest energy consumer which requires a rapid yet efficient action to prevent the energy leak; having this sector ruled by the sustainability laws will have a positive outcome in terms of overall national development and global wide emissions control.
\end{abstract}

Keywords: Glycine max, biosorption, cadmium, nickel, chromium, kinetics.

\section{Introduction}

\section{Definition of sustainability}

The rise of the concerns about environmental issues and natural resources exhaustion have contributed in the elaboration of the term sustainability that would put development on the right rails. The concept of sustainability was gradually addressed since Stockholm in 1972, Montreal in 1987, Rio de Janeiro in 1992, and Istanbul in 1996, until Kyoto in 1997. The meaning of the terms sustainability and sustainable housing is generally vague and not universally accepted $[1,2]$.
The most common definition of sustainable development is from the report Our Own Future by the World Commission in Environment and Development in 1987: "development that meets the needs of the present without compromising the ability of future generations to meet their own needs" $[3,4]$. Even though there are various interpretations of this definition, it is generally acknowledged that sustainability requires reconciling three pillars- environment, society and economy (Figure 1).

In 2006, the United Cities and Local Governments conference implemented culture as the fourth pillar for human rights and

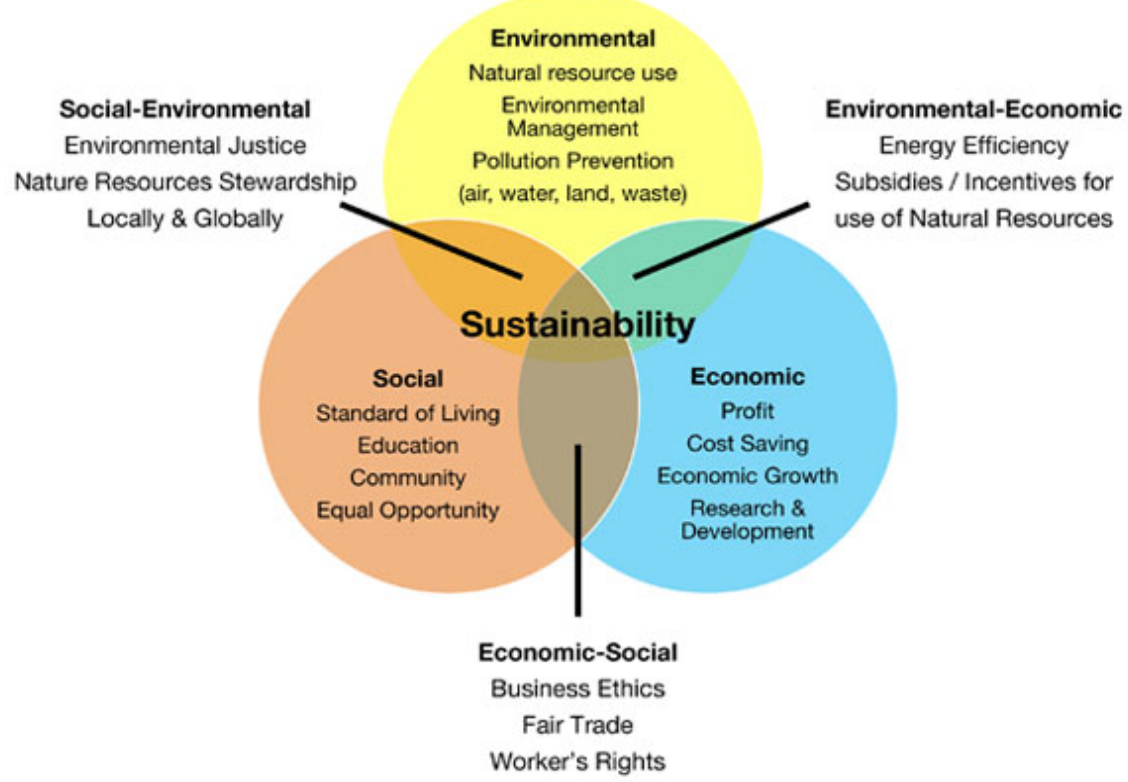

Figure 1. The three pillars of sustainability. 
cultural diversity [5]. Sustainability is thus viewed as a notion of multiple dimensions.

Sustainability is consistent with traditional ethics in China. The idea of harmony between humans and nature has been established in the traditional Chinese culture which is well reflected in its rich philosophical traditions-Taoism, Buddhism and Confucianism [6]. The Confucian scholar Mencius recognized the inseparable intimacy of humans and nature through the idea of the integration of the sky and human, which encourages human abeyance to objective natural laws and respect for metaphysical rules that people do not necessarily understand [7].

This reflects a respect for nature and the importance of working under natural rules rather than an emphasis on the dominance of humanity's presence. For neo-Confucians, human beings are organically connected with rocks, trees, and animals and form one body with the universe, philosophies that need to guide human development for the mutual benefit of all involved [8]. Taoism teaches that Man takes his law from the Earth; the Earth takes its law from Heaven; Heaven takes its law from the Tao (the Way or the Course). The law of the Tao is its being what it is [9]. These ideas of different schools illustrate the human relationship with nature, as everything grows in accordance with divine law, and everything is intrinsically interconnected. To conclude, the land-based livelihood of traditional Chinese society has established a rich compendium of knowledge on how to live relatively sustainably on the land over time [10].

However, Chinese traditions of collective responsibility and respect were largely erased in the twentieth century through radical campaigns, such as the purging of the Four Olds (old ideas, old culture, old customs and old habits) in the Cultural Revolution [11].

Since 1978, rapid industrialization and economic development has led to high pollution, high development in the last decades in China. In recent years, Chinese authorities have come to realize the importance of seeking a balance between unimpeded economic growth and enhanced environmental protection [12].

The definitions of sustainability by Chinese government are based on the definition given in the World Commission in Environment and Development conference, which are too vague and unclear to indicate the specific aims and strategies. In 1996, President Zemin Jiang declared that a sustainable development is the one that considers the current development needs without compromising the future generations needs [13]. This definition was further interpreted in the 2012 Peoples Republic of China National Report on Sustainable Development as increasing the total quality of life within the environmental carrying capacity and improving the efficiency of natural resource use to protect the ecological environment and coordinating the relationship of social and economic development and natural resources consumption [14]. The two definitions are closely linked to the directing political initiatives in China, but explicit goals and solutions are not explained; additionally, ecological philosophies embodied in traditional Chinese culture are not reflected in the definitions.
Bring together the international and Chinese definitions, this article defines sustainability as a long-term balance of four dimensions environmental, economic, social and cultural dimensions integrated to achieve environmental responsibility, economic viability, social equity and cultural viability. This definition is proposed based on the four pillars of sustainability and Chinese cultural tradition of balancing the whole system, in order to achieve the ultimate goal of creating a harmony relationship between human and nature. It embraces a comprehensive understanding of the current international agenda towards sustainable development and the Chinese context.

\section{Sustainable development in the Chinese Government perspective}

A review of policies and legislative initiatives in China demonstrates an active governmental response to global sustainability strategies, which delineates the practical and legal contexts of sustainable architectural practice. The internal and external pressures of sustainable development identified in this section require an immediate architectural response.

China's participation in milestone international conferences initiated the implementation of sustainable development discussed below, and laid the foundation for its national targets and strategies. In 1987, China was involved in compiling the UN Our Common Future report, and signed the Rio Declaration on Environment and Development and Agenda 21 in 1992 [15]. To strengthen its commitment to global sustainable development, the Chinese Government started to work on national policies, legislations and institutions to transform the methods of national development for economy, society and the environment [16].

In March 1994, China's Agenda 21- White Paper on China's Population, Environment and Development in the 21st Century was published; this is the first official guide document designed by the central government, aiming to set the national plans for economic and social development. In 1996, sustainable development was officially launched as one of the seven basic state policies. In 2000, China's government elaborated on sustainable development in its Five-Year Plan (2001-2005) for the first time, in which it addressed the goal of integral sustainable development in social, ecological and economic fields and made specific implementation targets of controlling the rate of population growth, protecting natural environment and reducing emissions [17]. Sustainable development in China was rekindled and prioritized by the 11th Five-Year Plan that proposed to build a harmonious, resource-efficient and environment friendly society in 2004 [18]. In the 12th FiveYear Plan (2011-2015), a more environmentally sustainable direction of the nation's development was initiated through the means of controlling the overall emission of pollutants; improving people's living quality by enhancing environmental management and protecting drinking water; promoting green development and environment protection; further establishing international cooperation to address global environmental issues $[19,20]$. The top-down policies on environment protection and sustainable development have improved significantly in the past decades in China, and its environmental legal framework has been much developed (Figure 2). 


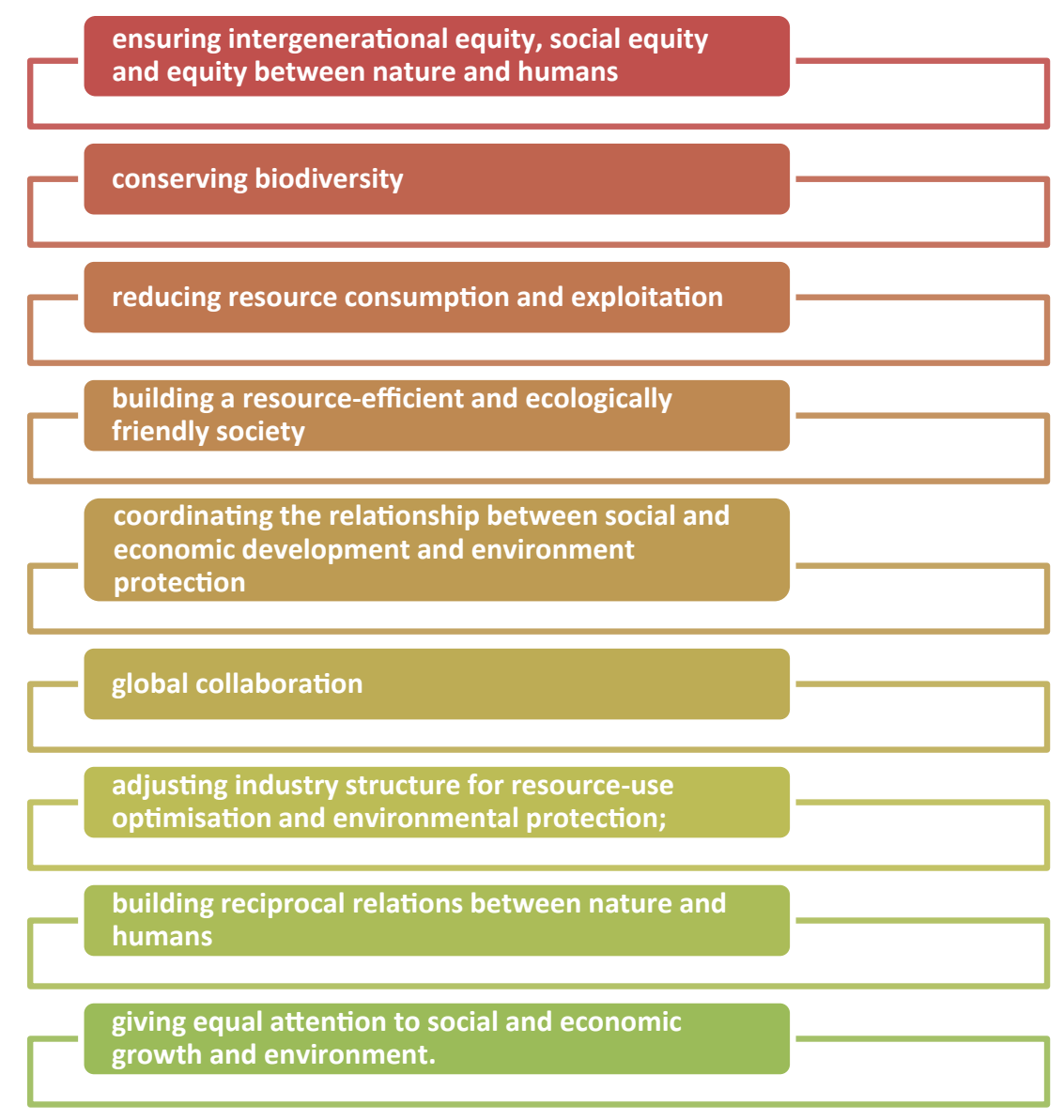

Figure 2. The pillars of sustainable development in China.

The principles of sustainable development in China have been refined to a set of more forward dimensions to direct all aspects of development in the latest government documents; these are summarised below:

Even with the Chinese government's rising awareness of environment protection and its great attention given to sustainable policies, there are remaining issues that impede the potential for larger-scale success and long-term sustainability [21]. Albeit the implementation of the sustainability policies since 1996, pollution, land degradation and water quality have rapidly deteriorated. There are three major issues found in China's current sustainable development agenda:

Firstly, the overall situation of environmental problems continues to intensify with increased national economic and social pressures, despite some achievements such as reduction of sulfuric dioxide emissions, improvement of environmental infrastructure and strengthened accountability and enforcement of environmental legislation over the past five years [22,23]. A series of serious pollution events- for example, the heavy smog and haze smothering most cities and water pollution became notable since 2014 have called into question China's current methods for tackling environmental issues (Figure 3).

Even though the 11th Five Year Plan has identified the significance to control air pollution, the outcomes are not positive and the overall environment quality is declining. The Asian Development Bank reported in 2013 that more than $99 \%$ of the 500 largest cities in China do not meet the air quality standards recommended by the World Health Organization, 7 of them are even among the 10 most polluted cities in the world [24]. Other urgent environmental problems in China involve serious crises in water pollution, water scarcity and solid waste disposal [25]. Moreover, this deteriorating overall situation is incurring significant economic costs. The annual economic costs of resource and environmental degradation were up to $13.5 \%$ of the GDP in 2005 [26]. The costs from premature death related to air pollution were estimated at 1.4 trillion US dollars in China in 2010 [27].

Secondly, energy consumption in China has increased rapidly over the past decade, as shown in Figure 2. China is still the largest energy consumer and producer in the world, and its depletion of natural resource and pollution is enormous [28]. The enormous consumption is related to its industrial process that supports not only national development and private consumption, but also global economic development [29]. As an important manufacturing centre in the world, the resource depletion and emission of pollutants in China are highly linked to the production of goods for export [30]. Besides, the nation's internal concerns for population growth, poverty eradication, urban-rural construction and economic development lead to further aggravation of ecological deterioration, as demonstrated by Richard Brubaker [31,32]. Per capita energy consumption rose by 297\% between 2003 and 2012 (Figures 4 and 5). 


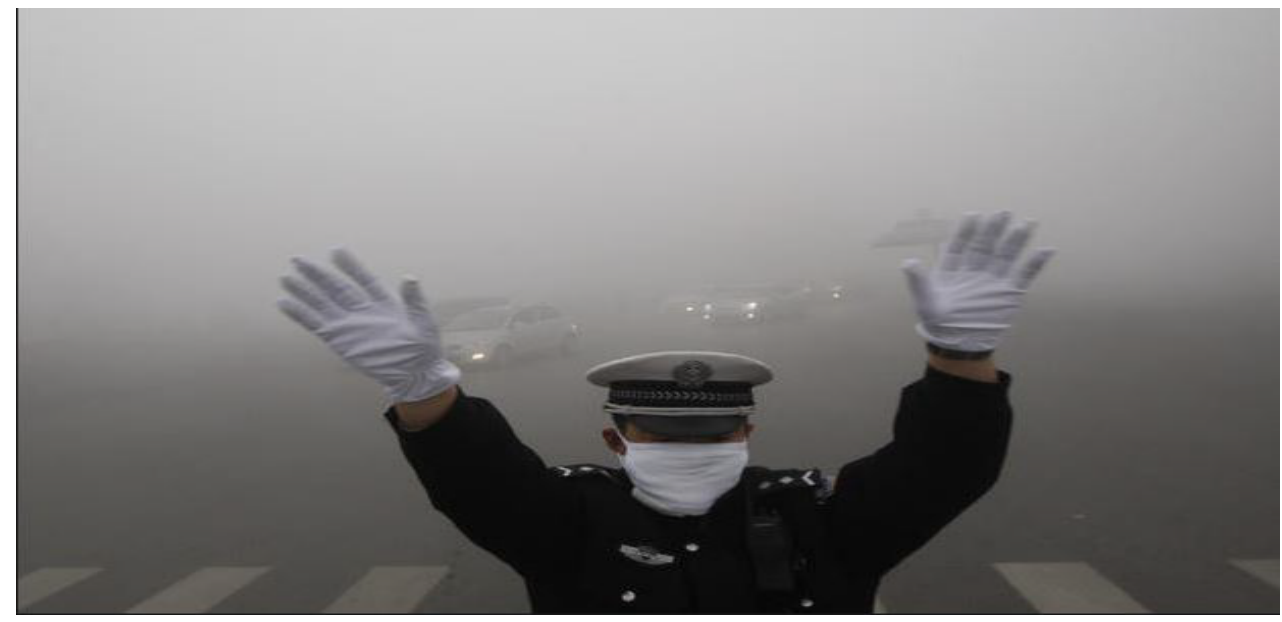

Figure 3. A traffic officer on duty during a foggy day in Harbin, Oct. 21, 2013.

Total Energy Consumption

(Unit:10,000 tons of Standard Coal Equivalent)

400000

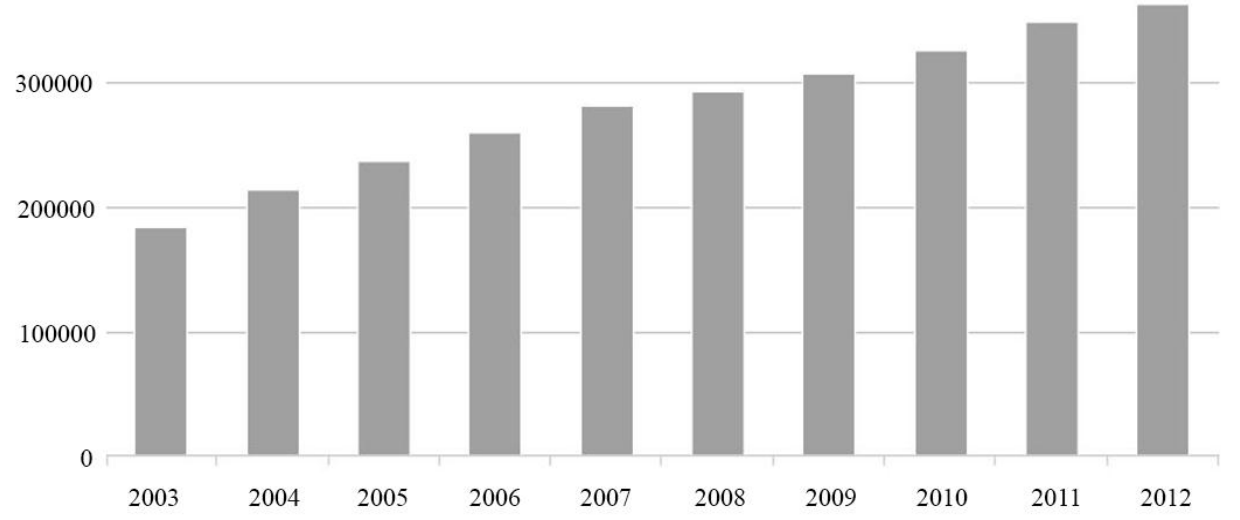

Figure 4. Total Energy Consumption in China 2003-12.

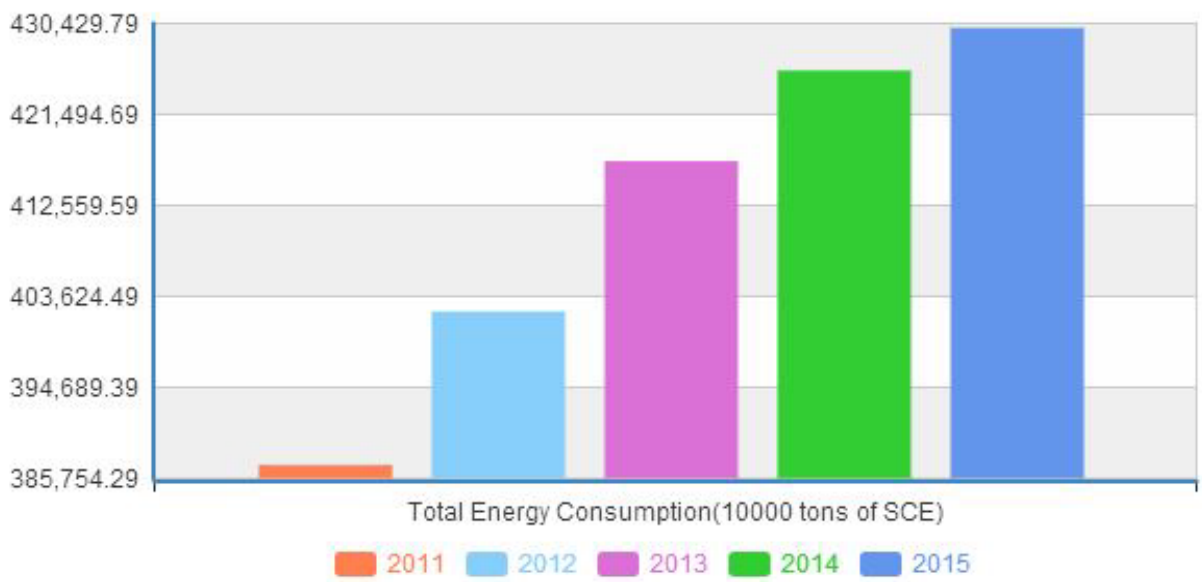

Figure 5. Total Energy Consumption in China 2011-15.

Continued reliance on coal and other fossil fuels as principle energy sources exacerbates environmental pollution, despite the comparatively tiny increase in alternative energy production such as wind, solar, hydro and nuclear power, as shown in Figures 6 and 7 [33]. Reliance on coal and fossil fuels also increases carbon dioxide emissions, which is a major cause of climate change.
Thirdly, China is facing the difficult of implementing and enforcing its policies and regulations, especially at the municipality and local level [34]. Due to their administrative hierarchy and lack of accountability for environmental regulation breaches, some local governments, as the Minister of Environmental Protection in China notes, give permission to polluting industries for instant economic benefits while lacking 
Energy Consumption

(Unit:10,000 tons of Standard Coal Equivalent)

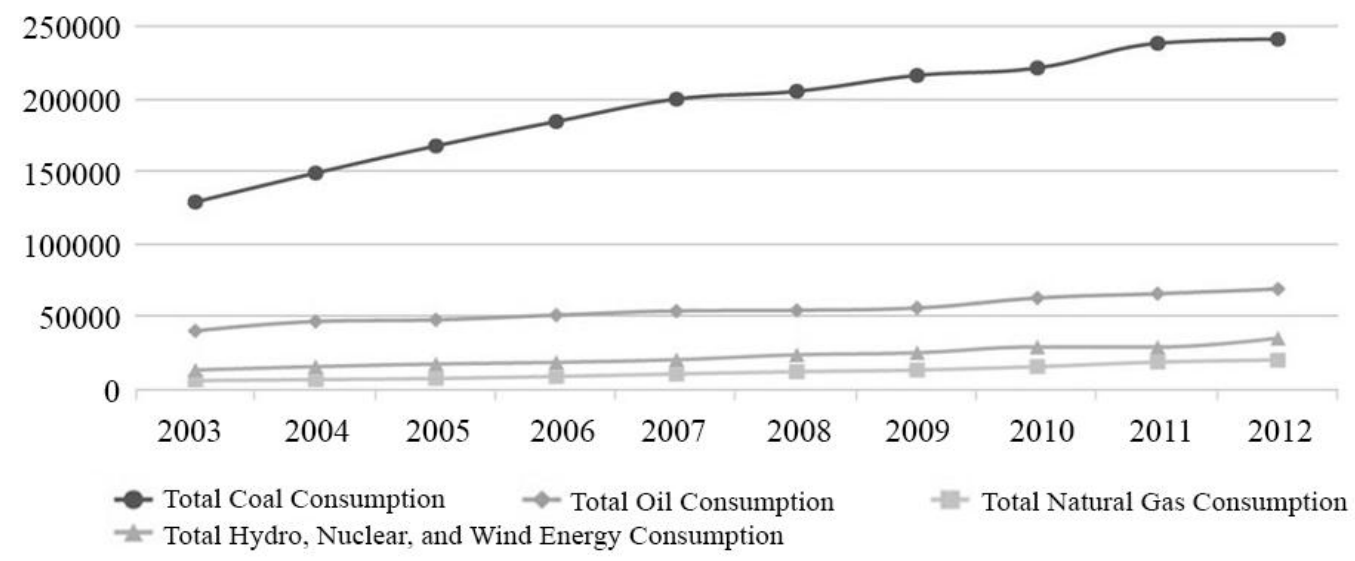

Figure 6. Components of the Energy Mix in China 2003-12.

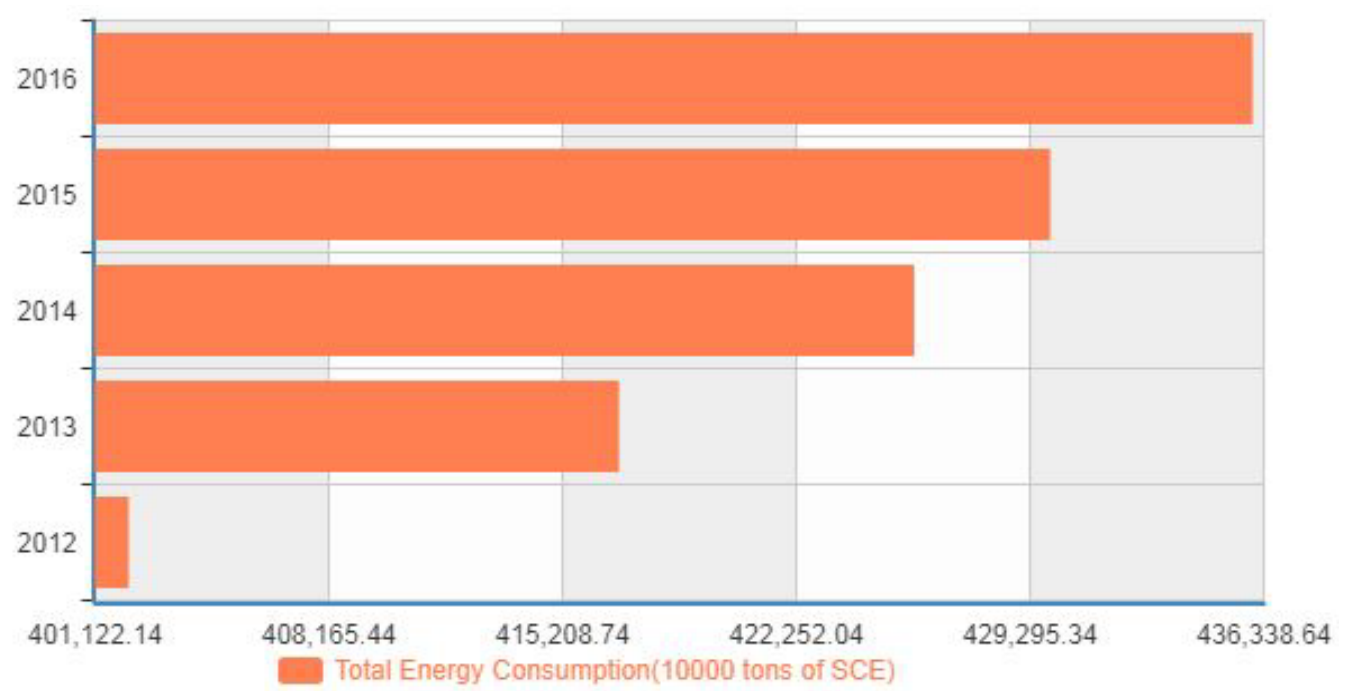

Figure 7. Total Energy Consumption in China 2011-15.

incentives to enforce national regulations for environment protection, and their short-sightedness leads to the incidence of environmental law offences and pollutions [35]. Another issue that also increases the difficulty of the regulations effective enforcement is that, there are sectoral and local regulations authored by different government departments at different phases- they are enforced by separate department and have different rules [36]. In 2013, Premier Keqiang Li expressed the resolution of the Chinese Government to take forceful measures to solve worsening pollution [37]. It is necessary to improve the government's performance comprehensively at multiple levels to conduct environmental supervision and administrative law enforcement at local levels [38].

\section{Summary of Chinese Efforts on Fulfiling the 2030 Agenda For Sustainable Development}

The Chinese president Xi Jinping has taken part of the United Nations Sustainable Development Summit that occurred in September 2015, side by side with other leaders, where he emphasized on the commitment of his country to the agenda.

China, as one of the largest economies of the world, has prioritized development and economy. And according to their 13th Five-Year
Plan approved in March 2016 by the National People's Congress, the development concept includes a number of relatively connected terms: innovation, coordination, green, open, and shared development. In the near future, the Chinese government aims to boost innovation and to improve the development's quality and efficiency, while coordinated development aims to ensure equal and well distributed development structure. The Chinese development will be directed towards a green, ecofriendly and low-carbon development model and lifestyle. The changes and improvements that china has promised will promote the process of opening-up to the world within a frame of a beneficial cooperation to all parties. China also wants to make sure that its development in the future will be shared which will improve people's wellbeing. The Chinese development will try to include a wide range of fields from the economic, cultural, social, political, to the ecological field to produce a coherent and balanced society on all levels (Figure 8).

China expressed its great interest in implementing the 2030 Agenda. It intends to fulfill the principles of Peaceful Development, Win-win Cooperation, Integration and Coordination, Inclusiveness and Openness, Sovereignty and Voluntary Action, as well as "Common but Differentiated Responsibilities", in order to build stronger bounds in 
Citation: Saiefeddine AM, Bouzoraa A, Xiaohu L. Zooming survey on the actual situation of the sustainable development in China from 1970 until now. Environ Risk Assess Remediat. 2018;2(2):51-59

Eradicating poverty and hunger through targeted measures

such as enhancing agricultural production capacities and food

security.

Improving social security and social services to ensure equal access to basic public services.

Establishing innovative strategies and encourage

sustainable, healthy and stable economic growth.

between urban and rural areas.

society's harmony and access to resources and development.

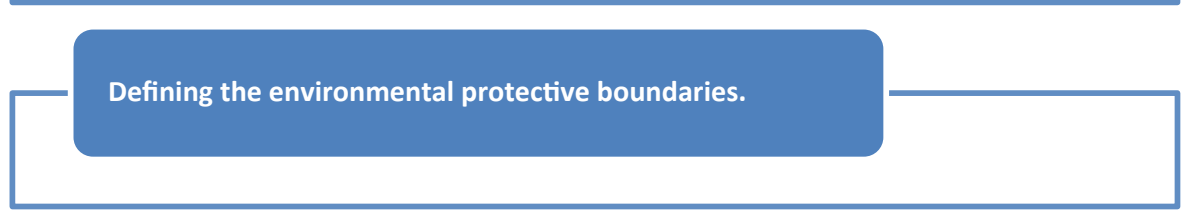

Confronting climate change efficiently and through oriented

strategies on the national level.

economic and social development within the frame of law.

prioritizing the green and sustainable energy resources.

Figure 8. The keys of the implementation of 2030 Agenda.

international relations with mutual benefits, establish cooperators on the globe scale, and achieve economic, social development all harmoniously with the environment.

China suggests 9 keys areas where the implementation of the 2030 Agenda should occur. They are as follows:

Many countries have taken steps forward in the process of internalizing the 2030 Agenda (Figure 9). The international community needs have set 5 dimensions as a general layout for the implementation:

The implementation of the 2030 Agenda for Sustainable Development has started since 2016. China, among others, has strongly contributed in the implementation of the 2030 Agenda in its mid-and-long term development strategies. The total of 43 government departments combined has been cooperating in order to guarantee the successful implementation. The 2030 Agenda has been strongly promoted nationwide to deploy internal resources, to raise the public awareness, and to create a favorable social environment. For this purpose, China will consolidate inter-sector coordination by the mean of new reoriented policies, and review related laws and regulations and set up an adequate legislative environment. As a short-term goal, China intends to move those below the current poverty line out of the extreme situation, and to double its GDP. The Position Paper was released in China on the Implementation of 
the 2030 Agenda for Sustainable Development. It declares the Chinese perspective and view regarding the principles, policies, priorities, and progress made in form of a UN General Assembly document to member states in April. It will be released as a national plan of implementing the 2030 Agenda by the end of 2018 to recapitalize how far the Chinese experience went [39].

This year, the Chinese president $\mathrm{Xi}$ is the paramount leader of the group of twenty. It allowed him to introduce the development issues into the G20 agenda. Thanks to the Chinese efforts, the Group of 2 has given the development issue a highlighted spot in its actual macro policy framework for the first time. The joint effort of the G20 members has produced a common draft action plan for the 2030 Agenda where political momentum should carry the implementation progress further on the 2030 Agenda. The G20 has also discussed Supporting Industrialization in Africa and Developing Countries to positively contribute in the development process in these countries, especially in Africa. China has also encouraged carrying dialogues with non-G20 countries. The number of the invited countries by China is the highest in all the G20's history which proves the Chinese intentions of introducing more participants in all activities this year, in order to guarantee that the G20's future actions fits the world's expectations.

China undertakes its own responsibilities as one of the largest developing country, and it promises to pursue its active contribution in the world wide development cooperation. It has supported more than 120 developing countries in order to achieve the Millennium Development Goals (MDGs). And about the future plans, China will strengthen its cooperation with the other developing countries to support the implementation of the 2030 Agenda. Today, China is putting into action the measures declared by President Xi Jinping at the UN Summits Marking the 70th Anniversary, by supporting other developing countries on the financial, technological and construction levels. More preparations for the Assistance Fund for SouthSouth Cooperation are taking place so it can be but into action in the near future. A new opportunity for the highly qualified brains of the developing countries has been settled with the foundation of The Academy of South-South Cooperation and Development in 2016. It provides doctor's degree and master's degree education and short-term training in the frame of a long term cooperative development. China has signed agreements on China-UN Peace and Development Fund with the UN; it was be put into action in 2016 and has started to fund projects that promote peace and development. China will also proceed with the one Belt one Road Initiative, and promote the Asian Infrastructure Investment Bank and the New Development Bank all along with other institutions so they can engage in a global development action plan.

\section{Conclusion}

The sustainable development process requires the combination of all available new means and technologies of coordination (Figure 10). In the future, China plans to carry on moving forward development and life quality by promoting green, eco-friendly development system. It will promote a balanced structure of sustainable development. China ensures it will undertake the task of implementing the 2030 Agenda for Sustainable Development, promote cooperative development with mutual benefit, and make joint efforts with other countries, developed and developing, to secure a sustainable development for the sake of the future generations.
Strength the building capacity of countries to

improve institution building, enhance the

public resources, and provide internal growth momentum.

create a worldwide environment for development, bulic

a balanced and win-win and provide a multilateral

trading system and increase global economic

governance.

cooperate with all stakeholders and work towards a

more equitable partnership for sustainble development

Promote for coordination mechanism and incorporate development policy into global macroeconomic policy.

Enhance the follow-up and conduct to a regular reviews

of global implementation progress while review of

national implementation would be done according to national conditions and the principle of voluntarism

action.

Figure 9. Layout of the process of internalizing the 2030 Agenda. 


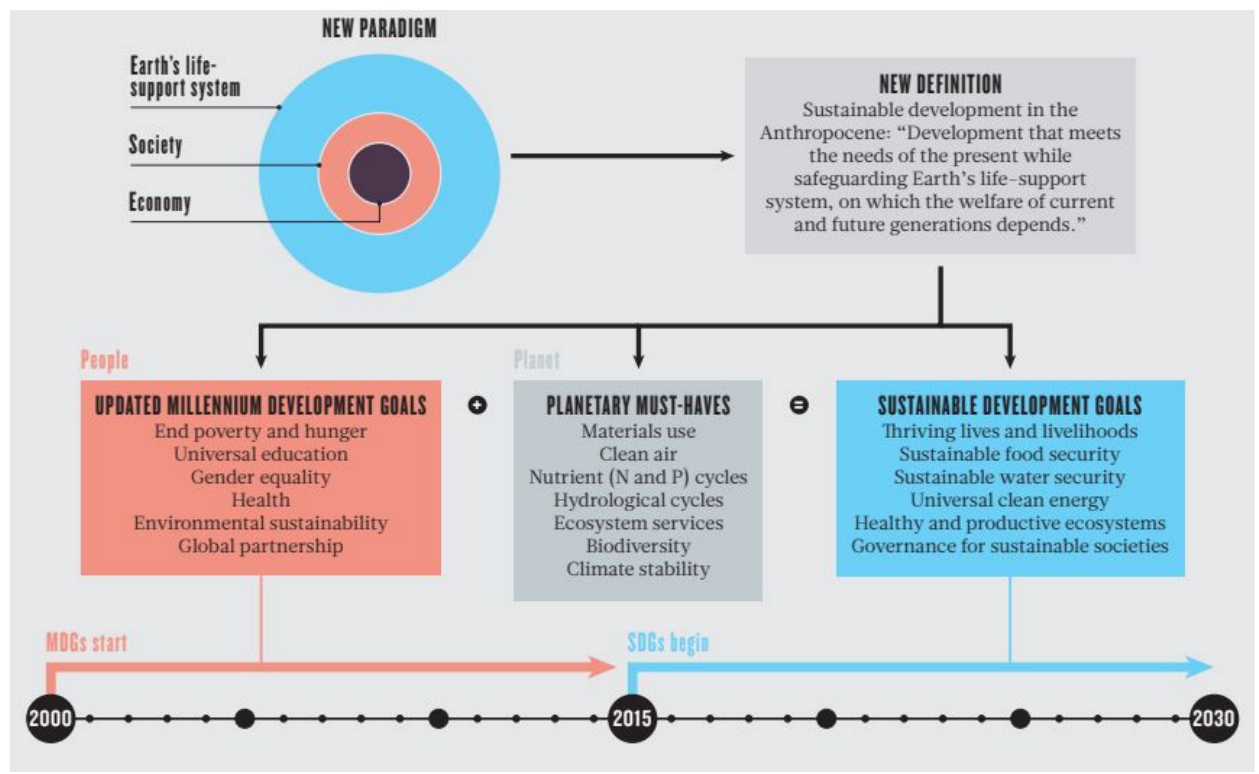

Figure 10. The sustainable development process.

\section{References}

1. Michael Standaert. China turns to clean tech to stimulate its economy. San Francisco Chronicle. 2009.

2. Jay J, Guo S. China's Environmental Crisis: Domestic and Global Political Impacts and Responses. New York: Palgrave Macmillan. 2010.

3. Farley HM, Smith ZA. Sustainability: If it's Everything, is it Nothing? New York: Routledge, 2013;5.

4. UNCEP, Our Common Future: World Commission on Environment and Development. Oxford; New York: Oxford University Press. 1987.

5. OECD, Sustainable Development: Critical Issues (Paris: Organization for Economic Cooperation and Development, 2001); United Nations General Assembly, World Summit Outcome, Resolution. 2005.

6. United Cities and Local Governments, Advice on Local Implementation of the Agenda 21 for Culture (document presented at the first meeting of the Committee on culture of UCLG, Barcelona, 2006); Key Ideas on the Agenda 21 for Culture. 2006.

7. Wen J. The People's Republic of China National Report on Sustainable Development. Beijing: The Central People's Government of the People's Republic of China. 2012.

8. Hou WH. Reflections on Chinese Traditional Ideas of Nature. Environmental History. 1997;2(4):483.

9. Weiming Tu. The Continuity of Being Chinese Visions of Nature, in Nature in Asian Traditions of Thought, ed. Mary Evelyn Tucker and John Berthrong. Albany, NY: State University of New York Press. 1989;113.

10. Laozi, Lau DC, Tao Te Ching. Baltimore: Penguin Books, 1963.

11. Böhm S, Bharucha ZP, Pretty J. Ecocultures: Blueprints for Sustainable Communities (New York: Routledge. 2015;15.
12. Bryan Tilt. The Struggle for Sustainability in Rural China: Environmental Values and Civil Society. New York: Columbia University Press. 2010;5.

13. Elizabeth Economy. The River Runs Black: The Environmental Challenge to China's Future (Ithaca: Cornell University Press. 2005;129.

14. http://rkj sw.sh.gov.cn/dr/impdoc/leader/ coreleader/2001-12-25/0010469.html?openpath=spfp/ impdoc/leader

15. Wen. The People's Republic of China National Report on Sustainable Development. 4.

16. Wang Yi, Sun H, Zhao J. Policy Review and Outlook on China's Sustainable Development since 1992. Chinese Geographical Science. 2012;22(4):382.

17. Rongji Zhu. Report About the Tenth Five-Year Plan of Civil Economic and Social Development, ed. State Council of the People's Republic of China. 2001.

18. CPGPRC. The Five-Year Plan of China (2005-2010). The Central People's Government of the People's Republic of China (Beijing: The Central People's Government of the People's Republic of China, 2004); The Five-Year Plan of China (2011-2015), ed. The Central People's Government of the People's Republic of China (Beijing: The Central People's Government of the People's Republic of China, 2010).

19. Zhang QF, Robert Crooks. Toward an Environmentally Sustainable Future: Country Environmental Analysis of the People's Republic of China. (Mandaluyong City, Philippines: Asian Development Bank, 2012), xx; CPGPRC, "The Five-Year Plans of People's Republic of China (2011-2015)," ed. The Central People's Government of the People's Republic of China. Beijing. 2011.

20. Zhang Crooks. Toward an Environmentally Sustainable Future: Country Environmental Analysis of the People's Republic of China. 
21. World Bank. China- Accelerating Household Access to Clean Cooking and Heating. 65.

22. CCICED. Assessment of Pollution Reduction in the 11th Five-Year Plan Period. Beijing: China Council for International Cooperation on Environment and Development. 2011;32.

23. http://www.theguardian.com/world/2014/feb/25/chinatoxic-air-pollution-nuclear-winter-scientists, http://edition. cnn.com/2014/02/24/world/asia/beijing-smog-solutions/

24. Zhang Crooks. Toward an Environmentally Sustainable Future: Country Environmental Analysis of the People's Republic of China. 55.

25. http://www.adb.org/news/green-tax-and-fiscal-reformneeded-green-growth-peoples-republic-china-adb-report

26. Zhang Crooks. Toward an Environmentally Sustainable Future: Country Environmental Analysis of the People Republic of China. 18.

27. UNEP. Unep Year Book 2014 Emerging Issues Update. Nairobi, Kenya: United Nations Environment Programme. $2014 ; 43$

28. http://www.eia.gov/countries/country-data.cfm?fips $=\mathrm{CH}$

29. http://www.theguardian.com/sustainable-business/blog/ china-sustainability-economy-environment-ecology

30. Zhang K, Wen Z. Review and Challenges of Policies of Environmental Protection and Sustainable Development in China. Journal of Environmental Management. 2008;88(4):1260.
31. Repetto R, Holmes T. The Role of Population in Resource Depletion in Developing Countries. Population and Development Review. 1983;9(4):609.

32. Kassiola JJ, Guo S. China's Environmental Crisis- A Global Crisis with Chinese Characteristics: From Confucius to Cell Phones," in China's Environmental Crisis: Domestic and Global Political Impacts and Responses. 2010.

33. Zhang Crooks. Toward an Environmentally Sustainable Future: Country Environmental Analysis of the People's Republic of China. 8.

34. Economy. The River Runs Black: The Environmental Challenge to China's Future. 101.

35. Dongna Di. China Punishes 1523 Cases of Environmental Offenses in 2013. Xinhua General News Service. 2014.

36. Zhang and Wen. Review and Challenges of Policies of Environmental Protection and Sustainable Development in China. 1251.

37. ht tp:// online.wsj.com/public/resources/ documents/2014GovtWorkReport_Eng.pdf

38. CPGPRC, Decision of the Central Committee of the Communist Party of China on Some Major Issues Concerning Comprehensively Deepening the Reform. Beijing: The Central People's Government of People's Republic of China. 2013.

39. http://www.fmprc.gov.cn/web/ziliao_674904/ zt_674979/dnzt_674981/qtzt/2030kcxfzyc_686343/ P020170414689023442403.pdf.

\section{*Correspondence to:}

Azaiez Mohamed Saiefeddine

School of Architecture \& Urban Planning

Huazhong University of Science and Technology

Wuhan

Alberta 430074

China

Tel: 008613129916940

E-mail: azaiez.architecte@yahoo.fr 